\title{
Monetary Conditions Index for Kenya
}

\author{
James K. Gichuki ${ }^{1, *}$ \& Eliud Dismas Moyi ${ }^{2}$ \\ ${ }^{1}$ School of Business, Department of Economics and National Development, Karatina \\ University, P. O Box 1957 - 10101, Karatina , Kenya \\ ${ }^{2}$ Macroeconomics Division, Kenya Institute for Public Policy Research and Analysis \\ (KIPPRA) \\ *Corresponding author: School of Business, Department of Economics and National \\ Development, Karatina University, P. O Box 1957 - 10101, Karatina, Kenya \\ Tel: 254-20-2176 713 E-mail: diajymes@gmail.com
}

Received: August 8, 2013 Accepted: September 16, 2013 Published: October 12, 2013

doi:10.5296/rae.v5i4.4099ＵRL: http://dx.doi.org/10.5296/rae.v5i4.4099

\begin{abstract}
The purpose of this paper is to construct and test the feasibility of a monetary conditions index (MCI) for Kenya using 2000 - 2011 time series quarterly data. Empirical results confirm the existence of cointegration between aggregate demand (GDP), the real exchange rate, the short-term interest rate and the claims on private sector. The last three variables are key in the monetary transmission mechanism for Kenya. Their relative strengths proceeds from the exchange rate, credit to private sector and the interest rates respectively. On the use of the monetary conditions index as an indicator, results show that it closely mirrors the movements of the interest rates while also closely tracking changes in the exchange rates. This makes its use in Kenya quite realistic since it would not be a radical departure from the use of the Central Bank of Kenya (CBK) rate.
\end{abstract}

Keywords: monetary policy; MCI; transmission mechanisms; Central Bank of Kenya 


\section{Introduction}

In pursuit of price stability, the Central Bank of Kenya (CBK) has over the years used either legislation or monetary policy instruments in the form of interest rates and monetary aggregates. However, in the face of increased financial transactions brought about by improved technology and the speed at which money moves across borders, the central bank's role in terms of monitoring and intervention are more challenging now than it was before. These changes weaken the link between monetary aggregates and inflation through an unpredictable demand function resulting from increased velocity of money. Despite the daily behavior of interest rates and exchange rates being more overt in most economies today, the Central Bank of Kenya still lacks an effective indicator of its intentions (both internally and externally) to financial markets. Furthermore, the CBK's occasional interventions are not pegged on optimum levels of exchange rates but on intuition (Oduor and Khainga, 2010). According to Ho (2010), economists are traditionally wary of discretionary monetary policy because it is uncertain if central bankers can read and interpret the signs correctly and respond accordingly.

In view of the foregoing, this paper constructs the monetary conditions index (MCI) and tests the feasibility of the index for Kenya to supplement the existing monetary framework. The MCI is a weighted measure of internal and external conditions through the interest rates and the exchange rates. A number of central banks such as those in Sweden, Canada and New Zealand as well as international financial institutions such as the IMF construct such an index and report on it. Its use in a small open economy like Kenya would help signal the inflationary pressures through aggregate demand but also assist financial markets to gauge the current stance of monetary policy.

\section{Central Bank of Kenya and the Conduct of Monetary Policy}

\subsection{Towards a Monetary Conditions Index}

The main objective of the Central Bank of Kenya is to formulate and implement monetary policy in order to achieve and maintain stability in the general level of prices (CBK, 2010). The CBK targets a 5\% level of inflation, which would ensure the growth of savings, investment and the economy while maintaining public confidence in the currency. Currently, the CBK has to carry out its role in an environment of increased financial transactions arising from improved technology, increased speed of movement of money across the boarders and a weakened relationship between the monetary aggregates and inflation. This calls for a tool that can be used by policy makers to signal any changes in the monetary conditions both internally and externally so that they can judge the extent by which adjustments are needed on the instruments of monetary policy.

Monetary conditions index is a simplified numerical indicator of the relative tightness or looseness of monetary policy. It captures the degree of pressure that monetary policy exerts on an economy's aggregate demand through changes in the interest rate and exchange rate, and hence on inflation. A weighted average of the interest rate and exchange rate, it is used by 
several central banks and international financial institutions (Ericsson et al, 1998). When properly used in a small open economy, it is serves to increase the transparency and credibility of monetary policy. However, if the central bank uses it poorly, it may increase confusion and distort the management of expectations incase the central bank reacts to every twist in the index (Siklos, 2000).

Since the liberalization of the exchange rate in Kenya in December 1993, there has been a debate on the appropriate level of exchange rate in Kenya as exporters complain when the currency appreciates and the importers take their turn when the shilling depreciates. This dilemma justifies the need for a monetary index. In 2011, the depreciation of Kenya's exchange rate caused uproar as the exchange rate reached an all time high of Kenya shillings (Ksh.) 101.27 to the dollar far above its 20 year average of $70.43 \mathrm{Ksh}$. to the dollar. According to Oduor and Khainga (2010), the Central Bank of Kenya's occasional interventions are not pegged on optimum levels of exchange rates but on intuition. This underscores the need for a yardstick or signal to help the central bank to determine the direction and extent of monetary policy interventions necessary to steer the exchange rate and economy back to equilibrium. Lack of an indicator in instances where there are misalignments and whether the misalignments are an over-appreciation or over-depreciation denies the policy maker an opportunity to optimally steer the exchange rate to the long-run equilibrium especially in response to external pressure. The MCI will also help in monitoring interest rate movements hence supplementing the use of the CBR which is currently the indicator of internal conditions.

The prominence of the exchange rate and interest rates in dealing with inflation and monetary policy in general cannot be refuted. In an open economy both the real interest rate and the real exchange rate are important factors in the determination of aggregate demand (Guender, 2005). Exchange rate movements indirectly affect aggregate demand and the spending behaviors of economic agents. For instance, in case the local currency depreciates, products in the local market will become cheaper to foreign buyers who increase local demand thus raising the domestic price levels. On the import side, this depreciation will increase the unit price of imported inputs thus increasing the cost of production and increasing inflation further. Buying and selling foreign exchange to and from the market helps CBK to influence inflation. Here, when CBK sells foreign exchange to banks, it withdraws the local currency from the market. Similarly, when CBK buys foreign exchange, it injects liquidity into the market.

The most important influence on demand is through interest rates since it affects portfolio choices in the market. If the interest rates (as reflected by the central bank rate (CBR)) are rising, representing a tight monetary stance, then the shilling appreciates. This causes market participants to sell dollars in order to obtain the shilling. As a result, there will be more dollars available in the market, causing the value of the dollar to decline, and vice versa. This shows that the interest rate and the exchange rate can work together to manage inflation and would come in handy in indicating the magnitude and direction of inflation. This would lay to rest the question of how much and when to alter monetary policy in response to inflation.

This paper seeks to construct and test the feasibility an MCI for Kenya to supplement the 
existing monetary framework while seeking to bridge the above mentioned policy gap. The theoretical argument to support the search for an alternative information variable is validated by various studies describing the inflationary process while maintaining a stable exchange rate in Kenya. Gichuki et al (2012) found that a composite index minimized losses from equilibrium output better than either the interest rate or the reserve money instruments taken independently. This study recommended the use of the monetary conditions index. Ndung'u (2000) in a study on the role of the exchange rates on inflation and monetary policy found that the exchange rate policy has not been supported by the appropriate monetary policy. Furthermore, it is currently the desire of CBK to focus "monetary policy on anchoring inflation expectations to low levels within the target and sustaining the stability of the exchange rate," (CBK, 2012). The monetary conditions index combining the interest rate and the exchange rate will therefore complement this effort.

\subsection{Monetary Policy Framework in Kenya}

Kenya is a small open economy with a liberalized capital market and a floating exchange rate. The exchange rate against other major currencies is market driven. A floating exchange rate policy was adopted in Kenya in 1993, allowing the Central Bank to conduct an independent monetary policy to fight inflation. The National Treasury specifies a price target to be pursued by the CBK, which then coordinates monetary policy and expectations towards the achievement of the target.

The direction of monetary policy in Kenya is signaled by movements in the Central Bank Rate (CBR), which indicates the monetary policy stance being pursued by the CBK. External shocks that affect the demand and supply of foreign exchange are reflected through the automatic adjustments on the exchange rate.

In formulating monetary policy, the CBK has at its disposal several policy instruments. These include the Open Market Operations, the discount window, reserve requirements among others. According to CBK (2012), the purchase and sale of foreign exchange from and to the market is an indirect tool of monetary policy. The CBR indicates the direction of monetary policy as set by the Monetary Policy Committee (MPC), and then the Central Bank applies appropriate tools to manage liquidity in the direction required by the monetary policy stance. Mainly, the CBK tries to control the monetary base or high powered money to determine the desired money stock in the economy.

The conduct of monetary policy in Kenya has gone through a raft of policy changes and reforms. In the 1960s after independence, there was a passive role of monetary policy since inflation was low (at 2 percent) and GDP growth was high (at 8 percent). The need for monetary policy intervention arose in the second decade when inflation became high fluctuating between 10 and 20 percent annually from the 1970s to the mid-1980s, and accelerated further to 47.7 percent in 1993. Policy intervention was needed after the 1973 oil crisis, the coffee boom of 1977/78 and the second oil crisis of 1979 which was accompanied by drought. The exchange rate regime was changed from a fixed to a crawling peg to deal with the appreciation of the real exchange rate. This was complemented with fiscal stabilization and interest rate adjustments. 


\section{Macrothink}

This cocktail of measures brought inflation down from 22 percent to 11 percent in 1982/83 (Legovini, 2002). It stayed below 20 percent up to the early 1990s when it recorded an annual average of 45 percent. Policy reforms were then implemented where the exchange rate regime was changed to a floating exchange rate among other measures. By 1995, all the foreign exchange restrictions had been eliminated, foreign exchange bureaus permitted and the Exchange Control Act repealed.

These changes in the policy regime laid the foundation for a decade of good performance in inflation management and output gains lasting until the end of 2007. The bedrock of this was a monetary framework which was successful in bringing inflation under control. This regime was organized around a broad-money anchor, with reserve money functioning as the operational target. Despite the efforts and gains described above, CBK'S objective of maintaining the inflation rate below the $5 \%$ target has for most years remained elusive as shown in figure 1.

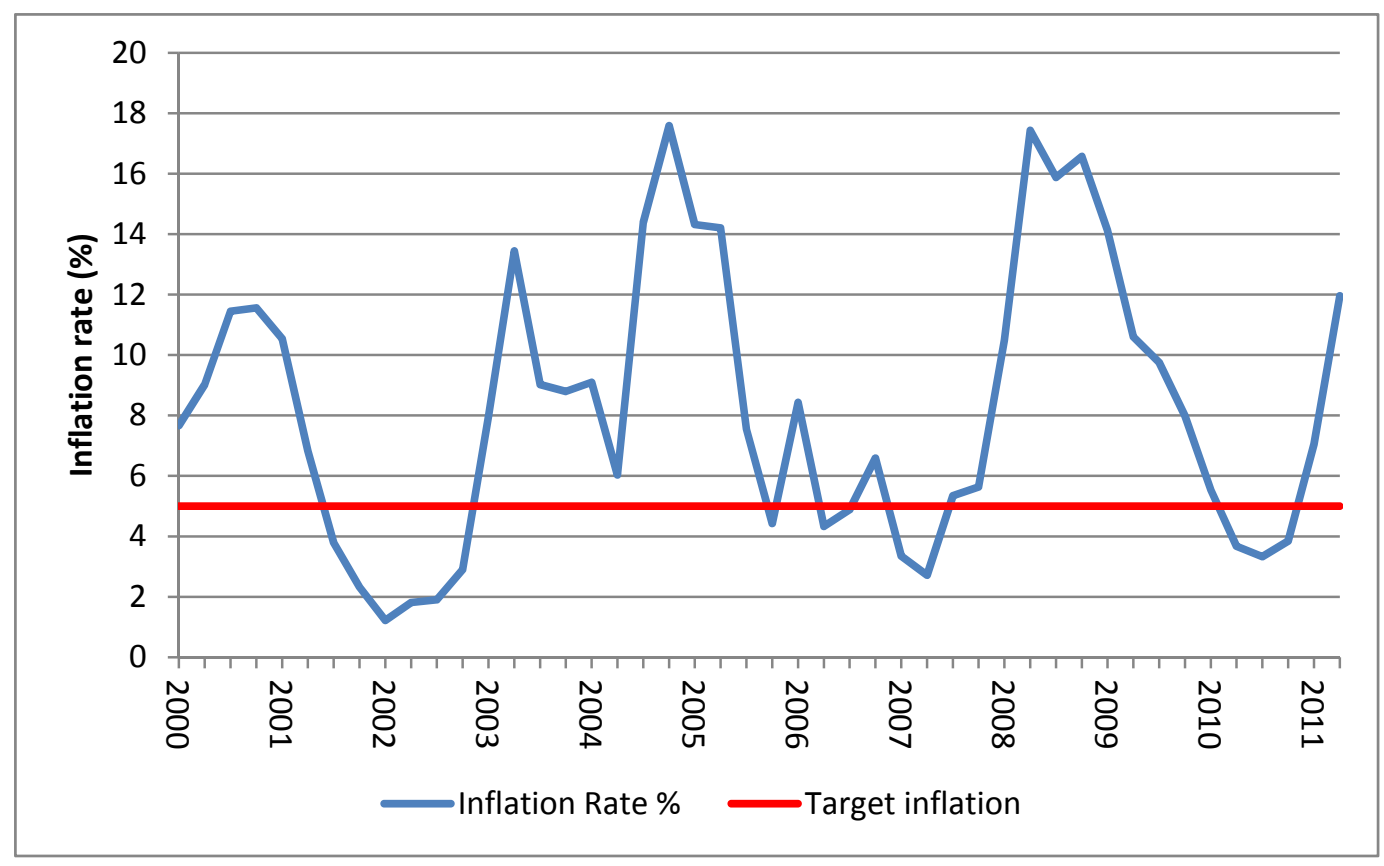

Figure 1: Trend of Inflation in Kenya

Figure 1 shows the nominal inflation rate and the target rate for Kenya between the year 2000 and June 2011. It shows that not only has the inflation rate stayed above the target for most of the time, but it also shows some volatility. Inflation in Kenya is driven by food prices (occasioned by drought, which affects agricultural output and necessitates food imports) and high crude oil prices. Therefore, a monetary policy that concentrates on interest rate movements and ignores the exchange rate is bound to be ineffective.

\section{Theoretical and Empirical Studies}

In the conduct of monetary policy, central banks the world over use different variables to play different roles. However, the operation of monetary policy can schematically be presented as 
follows;

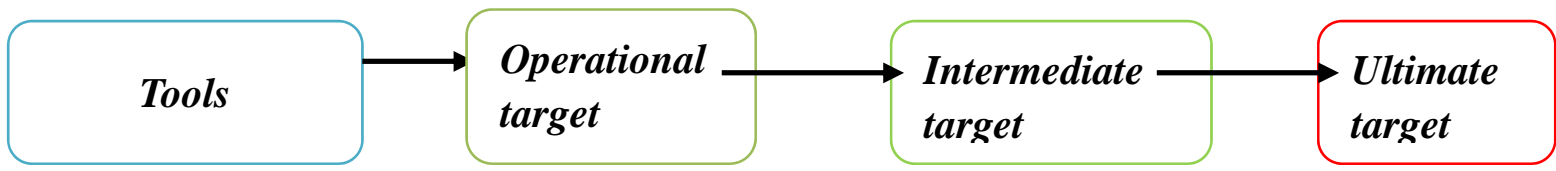

Figure 2: Monetary Transmission Mechanism

Central Banks usually have an ultimate goal to achieve such as price stability. To achieve this, the Central Bank starts with policy tools such as open market operations, the discount rate, the reserve requirement among others. Because of the long lags and indirect connection between the tool and the ultimate target, Central Banks use intervening variables to stand in between the ultimate target and the tools (Freedman, 1994). An intermediate target is a variable closely linked to the ultimate goal but can be influenced by policy instruments. It helps to adjust the instrument more quickly and more accurately in response to a shock to the system than it could if the Central Bank relied solely on the values of the ultimate target. Intermediate targets include broad money or high powered money, credit, exchange rate and inflation forecasts. Targeting one of these variables (e.g. broad money which is known to influence inflation) helps the central bank to respond more quickly than waiting to affect the ultimate goal. The operating target is usually treated as the instrument variable as in Poole (1970) and McCallum (2002) where short term interest rates and monetary aggregates were used. However, in the case of a country with a floating exchange rate, it is preferable to use a monetary conditions index as the operational target for policy rather than the short-term interest rate (Freedman, 1994).

For many years, Central Banks have used interest rates and monetary aggregates as operational targets. However, since its formulation, the monetary conditions index which is a combination of the short term interest rate and the exchange rate has become an operational instrument of policy and an indicator of the direction monetary policy. This has been occasioned by the need to identify alternative variables to function as intermediate operating targets and information variables in the conduct of monetary policy. The rationale for using the MCI has been propelled by two issues in the policy making process. First, financial market liberalization and deregulation in Kenya during the early 1990s has weakened the relationship between monetary aggregates as intermediate targets to inflation. The second issue is the need to measure the influence of exchange rate changes on inflation. However, the need for an instrument that indicates by how much policy should change has been long overdue as indicated by Friedman when he argued that policy rules are desirable when the authorities don't have the information or capability to know when or by how much to stimulate or dampen the economy without which, activist stabilization policies can end up exacerbating the very economic volatility they seek to reduce (Adam et al, 2011).

In conducting monetary policy, central banks try to marry the short term objective of reacting 
efficiently and flexibly to economic shocks and the long-term objective of securing low and stable inflation. According to Mahadeva and Stern (2000) monetary policy is simple where there is a single objective, a single instrument and policy makers had available a model that accurately comprehensively and transparently models the transmission mechanism of money. In a regime of floating exchange rates and mobile capital, both interest rates and the exchange rates are important components in the transmission of monetary policy to inflation.

A number of Central Banks, international organizations, and private sector financial organizations have adopted the MCI. MCIs may be rated superior to Central Bank setting the instrument alone (Mahadeva and Stern, 2000). The two variables are chosen as they reflect the main channels of transmission of monetary policy to inflation. Used together in the MCI, they come with the advantage of simplicity but the setback of estimation difficulties and interpretation.

In their description of the monetary conditions index, Osborne-Kinch and Holton (2010) identify three ways of arriving at the weights of the MCI namely the single equation estimation, multiple equation based MCIs, and trade share based MCIs. They identify the single equation approach as the most common. The multiple equation based MCIs involve obtaining the weights from macro-econometric models with a number of equations or using vector autoregressions (VARS) relationships of GDP, exchange rates and interest rates . Trade share based MCIs are simpler to obtain. The exchange rate weight is based on the long run exports-to-GDP ratio and the interest rate weight obtained by one minus this ratio. Trade share based MCIs are criticized for their lack of detail about the effects of the relevant variables on the economy.

Okello and Opolot (2009) estimated the MCI using a reduced form of multiple equations. They argued that the multiple equations method was preferred as it captured the effects of foreign prices and interest rates on the domestic price level given that Uganda is a small open economy. Their finding was that the MCI ably captured the changes in domestic and external conditions and preferred it to the monetary aggregates M2 and M3 as an indicator of the monetary conditions given its frequent calculation. However, the monetary conditions index may not be used in isolation as an indicator or as an operating target in influencing inflation.

Kannan et al (2006) estimated a broad MCI incorporating credit growth as an additional indicator of monetary conditions for India. Their results revealed that the interest rate was more important than exchange rate in influencing monetary conditions in India. They found the MCI more effective to put together than any single indicator in order to provide a better assessment of the stance of monetary policy and demonstrated its role as a leading indicator of economic activity and inflation. While conceding that the MCI may not be the single solution to monetary policy conflicts, it systematically takes into account both easing and tightening of monetary conditions (and even credit, in case of broad MCI) so that there is no room for missing such counter-movements.

Toroj (2008) used four empirical strategies (IS and Phillips curve, VAR model and small structural system of equations) to evaluate relative importance of the real interest rate and the real exchange rate in determining the output gap as a basis of computing the monetary 
conditions index (MCI). The weights for the real interest rate varied from 0.279 to 0.669 , whereby most of the methods indicate a bigger role for the real interest rate. A higher weight attributed to the real interest rate in most outcomes could suggest a risk of a macroeconomic overheating or overcooling in the case of a cyclical divergence between Poland and the rest of EMU in a currency union. The research proposed that endogenous effects of monetary union membership could change the way that macroeconomic mechanisms work, so that real exchange rate channel is widely considered to be at work in the long run.

Kodra (2011) used ordinary least squares estimation for quarterly data between 1998 and 2008 for Albania to assess the relative weights of the real interest rates and the real exchange rate in the MCI. This study found a weight of 3.8 for the exchange rate meaning that the effect of an appreciation of the real exchange rate by 3.8 percentage points could be neutralized by one percentage point increase in the real interest rate. The interest rate here had more effect as expected over the exchange rate. However, this study found interest rates to have been losing ground in their impact on financial conditions overtime.

\section{Computation of the MCI}

Following Guender (2005) the MCI is computed from a simple aggregate demand function presented as;

$$
y_{t}=-a r_{t}-b e_{t}+v_{t} \quad a, b>0
$$

Where;

$\mathrm{y}_{\mathrm{t}}$ is the GDP calculated as the ratio of nominal GDP to consumer price index CPI

$r_{t}$ is the interest rates calculated by the by the 91-day Treasury bill rate minus CPI

$e_{t}$ denotes the real exchange rate as units of the Kenya shilling against the American dollar

$v_{t}$ captures other factors that influence aggregate demand

All the variables are expressed in logarithm form apart from the interest rate and by definition all series are in real terms. The parameters $a$ and $b$ represent the coefficients for interest rate and the exchange rate in the demand equation, which are used to derive the weights of the MCI.

The size of $a$ and $b$ reflect the relative effect of the real interest rate and the real exchange rate on aggregate demand. These two parameters are then used in the generation of an MCI as follows;

$$
M C I_{t}=\alpha\left(r_{t}-r_{0}\right)+\beta\left(e_{t}-e_{0}\right), \quad \alpha+\beta=1
$$

In this case, subscript $t$ is a time index and 0 the base period, $\alpha=\frac{a}{a+b}$ and $\beta=\frac{b}{a+b}$. The interest rate is measured in percentage points while the exchange rate appears in index form 
with 100 being its level (in percentage points) in the base year. The MCI will be computed using quarterly data between 2000 and 2011. Selection of the base is arbitrary. An increase in the MCI reflects tightening while a decrease in the MCI reflects easing of the monetary conditions. Tightening is done through an increase in local interest rates which induces capital inflows and consequently leads to an appreciation of the domestic exchange rate (Poon, 2012). Exchange rate appreciation makes the current account worse off and hence tightening the monetary conditions serves to reduce aggregate demand and vice versa.

\section{Empirical Results}

The augmented Dickey Fuller (ADF), and Kwiatkowski, Phillips, Schmidt and Shin (KPSS) are used to test for the presence of unit roots. Results in the following table show the rejection of the null hypothesis at first difference meaning that the series are all I(1).

Table 1: Unit Root Tests

\begin{tabular}{lllll}
\hline \multicolumn{3}{c}{ ADF } & & KPSS \\
\hline & Level & First difference & Level & First difference \\
$y$ & $0.12(9)$ & $-8.51(9)$ & 0.84 & 0.08 \\
$r$ & $-3.20(9)$ & $-4.23(9)$ & 0.22 & 0.08 \\
$e$ & $-2.35(9)$ & $-5.67(9)$ & 0.12 & 0.14 \\
At 1\% & -2.62 & -2.62 & 0.74 & 0.74 \\
At 5\% & -1.95 & -1.95 & 0.46 & 0.46 \\
\hline
\end{tabular}

Having established that the variables were integrated of the same order, a cointegration test was necessary to determine if the variables had a long run steady state using the Engel Granger Test. Equation (1) was first estimated and then the residuals generated tested for unit roots. The unit roots tests done by KPSS showed that the variables were cointegrated since the computed test statistic was 0.182 compared to the critical values of 0.463 at $5 \%$ and 0.739 at $1 \%$.

\subsection{Estimation of the Weights}

We run a regression of an augmented version of equation (1) to yield the following results (prob-values of the estimates are shown in brackets below the estimated coefficients);

$$
\begin{gathered}
y_{t}=11.52730152-0.004643375632 r_{t}-0.1924116517 e_{t}+0.1499723741 c_{t} \\
(0.0012)
\end{gathered}
$$

Where $y_{t}$ represents log real GDP, $r_{t}$ represents the real 91-day treasury bill rate, $e_{t}$ the log real exchange rate and $c_{t} \log$ credit on private sector. Equation 3 shows that the coefficients were all statistically significant based on the prob values.

Taking the parameters in equation 3 and using them as inputs in equation 2 yields: 


$$
M C I_{t}=0.0234\left(r_{t}-r_{0}\right)+0.9766\left(e_{t}-e_{0}\right)
$$

The weight of $e$ (or 0.9766) divided by the weight of $r$ (or 0.0234 ), or vice versa, yields the MCI ratio. In this case, the MCI was 41.735 which was the equivalent of 0.024 when expressed as the weight of the interest rate $(r)$ over the exchange rate $(e)$. This result therefore suggests that a one percent point rise in the interest rate has the same effect on GDP as a 0.024 percent rise in the exchange rate (depreciation). Conversely, a percentage point depreciation has the same effect on the MCI as the 41.735 percent point increase in the real interest rate, all other factors held constant.

The interest rate has a lower weight compared to the exchange rate meaning that a percentage point change in interest rate has a lesser effect on output than a one percent change in the exchange rate. This finding is consistent with Peng's (2000) finding that the estimates for small open economies produce smaller ratios of the real interest rates compared to the exchange rates.

Whether or not the estimated MCI fits the monetary policies of the CBK in the period can be seen through a visual inspection of the Figure 3 to see whether CBK responded to prevailing economic times in the pattern described by the MCI. This is shown by plotting the 91-day Treasury bill rate, the MCI and the real exchange rate on the same axis. The MCI tracks the changes in the interest rate quite effectively as well as the exchange rate.

The MCI tracks the interest rates really well. Despite Kenya maintaining a floating exchange rate, the MCI shows relative stability in the period covered. Since a rise in the MCI should reflect a tightening in monetary conditions and vice versa, Figure 3 shows that the central bank has pursued a tightening of monetary policy stance since a trend line generated on the MCI generates a negative slope.

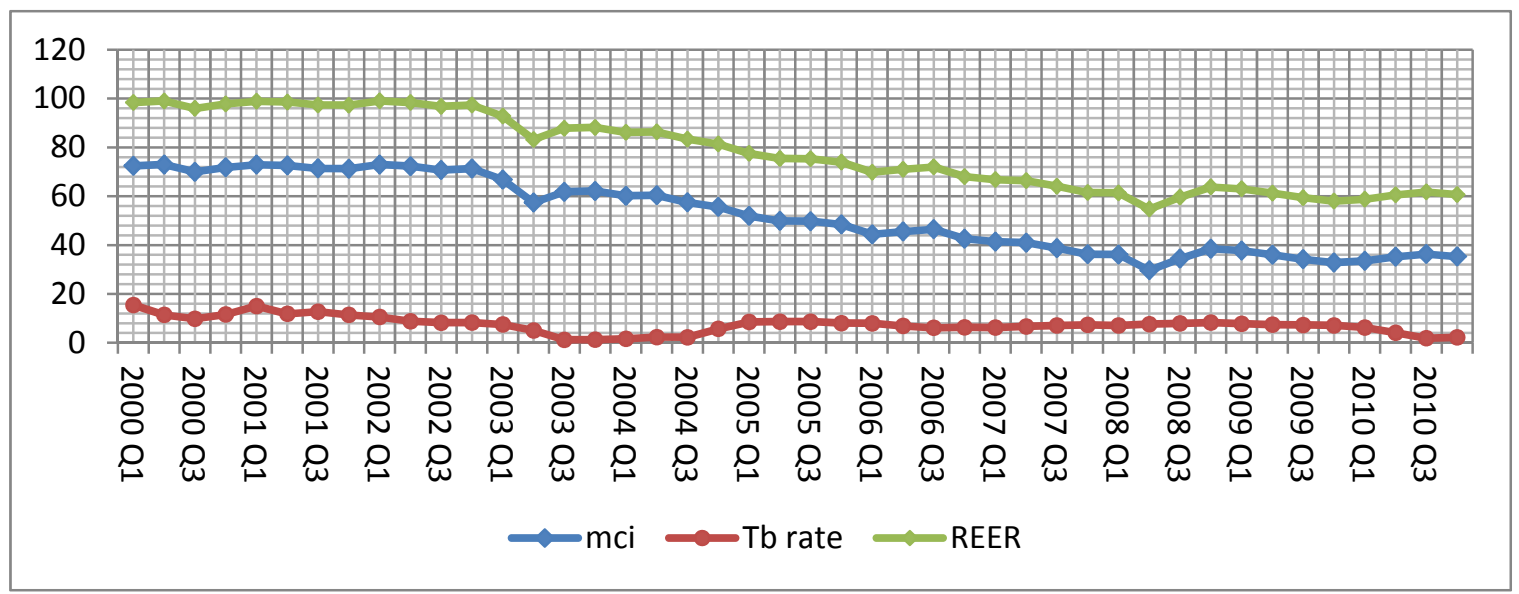

Figure 3: Computed MCI and Contributions from Its Components

\section{Conclusion and Policy Implications}

The purpose of this study was to examine the feasibility of an MCI in the conduct of 
monetary policy in Kenya using 2000 to 2011 quarterly data. The results indicated the presence of cointegration between real GDP and the exogenous variables namely the interest rates, exchange rates and claims on private sector. This implies that the three variables are the main channels of monetary policy transmission in Kenya.

The relative strength of the transmission mechanism on aggregate demand among the three variables proceeded from exchange rate, the credit channel and interest rates. Overall, the results indicated that the MCI responded to the interest rates reasonably well and leads to the following policy deductions.

As a guide to monetary policy stance, MCI is an indicator that can be used to monitor the interest rate and exchange rate movements and their effect on the aggregate demand and eventually, on inflation. This study has established that MCI movements are more responsive to interest rates. This means that interest rates can be used as a reliable indicator of monetary policy stance. This also implies that rather than use the interest rates, the MCI would still serve to lessen overreliance on the interest rates to stabilize output and by extension inflation.

A percentage point change in the exchange rate has more impact on aggregate demand than interest rates. This means that the exchange rate channel has a faster impact than the interest rate on aggregate demand pressures. This intuitively means that a strong shilling would be a good way to keep inflation at bay while providing some still waters for an overheating economy. The caution, however, in the use of the exchange rates would be the fact that the policy maker has to identify the source of the exchange rate movement then decide on the size and direction of the interest rate movement to offset the change.

\section{References}

Adam, C. S., Maturu, B. O., Ndung’u, N. S., \& S.A. O’Connell. (2011). "Building a Kenyan Monetary Regime for the Twenty-first Century”. In C.S. Adam, P. Collier and N.S. Ndung'u (eds) Kenya: Policies for Prosperity Oxford: Oxford University Press.

Apaa-Okelloa, J., \& Opolot, J. (2009). Monetary conditions index for Uganda. The Bank of Uganda Journal, 4(1), 58-80.

Ericsson, N., Jansen, E., Kerbeshian, N., \& Nymoen, R. (1998, August). Interpreting a monetary conditions index in economic policy. In Bank for International Settlements Conference Papers (Vol. 6).

Gichuki, J., Oduor, J., \& Kosimbei, G. (2012). The choice of optimal monetary policy instrument for Kenya. International Journal of Economics and Management Sciences, 1(9), 1-23.

Guender, A. V. (2005). Monetary Conditions Index. An Entry Prepared for the Princeton Encyclopedia of the World Economy, Retrieved from www.world-economics.org

Kannan, R., Sanyal, S., \& Bhoi, B. B. (2006). Monetary conditions index for India. Reserve Bank of India occasional papers, 27(3), 57-86. 
Kodra, O. (2011). Estimation of weights for the monetary conditions index in Albania. Economic Research Department, Special Studies Division, Bank of Greece, Athens, Greece.

Legovini, A. (2002): “Kenya: Macro Economic Evolution since Independence”, Work Financed by UNDP.

Mahadeva, L., \& G. Sterne 2000. “The Devil in the Detail of Monetary Policy Frameworks (2): Interpreting Measures of Framework Characteristics.” Monetary Policy Frameworks in a Global Context, Routledge, London.

McCallum, B. T. (2002). "Monetary Policy rules and the Japanese Deflation”. Conference Paper for the March 20, 2002 workshop sponsored by the Economic and Social Research Institute of the Japanese Government.

Oduor J., \& Khainga D. (2010). "Equilibrium Real Exchange Rates and Real Misalignment in Kenya: A Fundamental Equilibrium Approach.” Kenya Institute for Public Policy Research and Analysis (KIPPRA), Discussion Paper No 108. Nairobi, Kenya.

Osborne-Kinch, J., \& Holton, S. (2010). “A Discussion of the Monetary Condition Index”, Quarterly Bulletin 01, Central Bank \& Financial Services Authority of Ireland (Publications), pp 68-80.

Poole, W. (1970). Optimal Choice of Monetary Policy Instruments in a Simple Stochastic Macro Model. Quarterly Journal of Economics, 84, 197-216. http://dx.doi.org/10.2307/1883009

Poon, W. C. (2012). A Monetary Policy Rule: The AMCI for the Philippines Using UECM and Bounds Test. The IUP Journal of Bank Management, 10(4), 16-30.

Siklos, P. L. (2000). Is the MCI a useful signal of monetary policy conditions? An empirical investigation. International $\quad$ Finance, 3(3), 413-437. http://dx.doi.org/10.1111/1468-2362.00059

Toroj, A. (2008). "Estimation of weights for the Monetary Conditions Index in Poland", Warsaw School of Economics, Department of Applied Econometrics, Working Paper No 6-08.

\section{Copyright Disclaimer}

Copyright reserved by the author(s).

This article is an open-access article distributed under the terms and conditions of the Creative Commons Attribution license (http://creativecommons.org/licenses/by/3.0/). 